\title{
«MÉDULA EN TRADUCCIÓN» RILKE, CREELEY Y JACCOTTET EN TRES POETAS ESPAÑOLES \\ (JUAN ANDRÉS GARCÍA ROMÁN, MARCOS CANTELI Y RAFAEL JOSÉ DÍAZ)
}

\author{
Mario Martín Gijón
}

\begin{abstract}
This paper analyses the translations from Rainer Maria Rilke by Juan Andrés García Román, from Robert Creeley by Marcos Canteli and from Philippe Jaccottet by Rafael-José Díaz. It intends to analyse the reasons and consequences of a poet's dedication to translation. In these three cases, the paper observes the different ways of translation by these poets and the relation of their translations to their own literary works. This intensive dedication to the translation of three great poets of German, English and French literatures shows the breadth of interests of the most innovating authors in contemporary Spanish poetry.

Keywords: Spanish poetry; $X X^{\text {th }}-X X I^{\text {th }}$ centuries; translation; comparative literature.

Resumen: Este artículo analiza las traducciones de tres poetas llevadas a cabo por tres jóvenes poetas españoles: Rainer Maria Rilke por Juan Andrés García Román, Robert Creeley por Marcos Canteli y Philippe Jaccottet por Rafael-José Díaz. Se pretende indagar sobre los motivos y repercusiones de la labor traductora de un poeta. En los tres casos, comprobaremos las distintas técnicas de traducción de estos poetas y cómo sus traducciones están relacionadas con su propia obra poética. La dedicación intensiva a la traducción de tres grandes poetas de las literaturas de lengua alemana, inglesa y francesa muestra la amplitud de intereses por los poetas más innovadores en la poesía española contemporánea.
\end{abstract}

Palabras clave: Poesía española; siglos XX-XXI; traducción; literatura comparada.

\section{Introducción}

En el panorama poético español coexisten desde hace ya décadas varias corrientes, deudoras de distintas concepciones de la actividad poética. En la última década hemos asistido a la maduración de la obra de un grupo de jóvenes autores que ha renovado la reflexión crítica sobre el lenguaje visto como un centro de conflictos. Entre estos poetas, puede verse una dedicación notable a la traducción de poesía, muy superior a la observada en otras corrientes poéticas, así como una gran diversidad de intereses, en la cual los referentes poéticos se buscan en las tradiciones literarias más dispares, sin ningún consenso previo y dejando en ello actuar a la experiencia personal. 
En este ensayo se ha seleccionado a tres de los poetas españoles más reconocidos de entre los que comenzaron a publicar en la década de los noventa: Juan Andrés García Román, Marcos Canteli y Rafael-José Díaz. Todos ellos han dedicado notable atención a la traducción poética, de manera paralela a su propia obra lírica. En los tres casos, se ha podido constatar una afinidad especial con un poeta al que han consagrado su más amplio trabajo como traductores. Respectivamente, se abordarán las traducciones de los siguientes autores: Rainer Maria Rilke, Robert Creeley y Philippe Jaccottet. Se trata, como puede verse, de tres autores de tres literaturas distintas, con los problemas consecuentes a sus lenguas de origen.

Mi enfoque, más que dentro de la traductología, sin embargo, se sitúa en el ámbito filológico: lo que me interesa es dilucidar cómo surgen en el campo poético afinidades electivas entre traductor y poeta traducido, y cómo la obra de un poeta y sus traducciones se integran en un mismo proyecto creador.

\section{2. «El centro trashumante» de Rilke a García Román}

En el caso de Juan Andrés García Román (Granada, 1979), sus traducciones de Rilke se explican por una «afinidad esencial» (Mora 2009) sentida hacia la poética del autor alemán ${ }^{1}$, cuya obra conoció el poeta granadino durante su estancia de estudios en la Universidad de Heidelberg, y en la que profundizó, ya como doctorando en Teoría de la Literatura, en la Universidad de Kiel, donde inició sus traducciones del poeta praguense. Según el poeta granadino, el conocimiento de Rilke fue crucial en la evolución que se percibe entre su poemario Las canciones de Lázaro (2005) y Launa (2006), al pasar de una poesía más romántica y contemplativa a la conciencia del desgajamiento del «yo» respecto a la naturaleza y la necesidad de colmar esta distancia:

Esa distancia que separaba siempre al yo de lo otro [...] y la necesidad de romperla, de atravesarla, había sido precisamente advertida por el discurso de la poesía moderna, por Rilke, entre otros, para quien el ser humano era una criatura anhelante de la «sublime indiferencia de la naturaleza», de la «tranquilidad de las cosas»: «sólo los dioses son -dirá el maestro-, nosotros transitamos por entre sus espejos / sobre un fondo de plantas y animales» [...] a partir de aquí, a partir de la ruptura con el yo, con el relato de la primera persona como discurso consubstancial a la poesía, se abría un territorio aplastantemente vasto. Un «centro trashumante» (Launa) era el poema para mí (García Román 2008: 223).

Asimismo, García Román (2008: 224) afirma que la idea rilkeana del Ding-Gedicht, o «poema-cosa», le sirvió para un proceso de objetivación de la mirada y de «búsqueda de un equilibro prístico con las cosas» que puso en marcha la indagación reflejada en su diario poético Launa. Aunque García Román, que además de Rilke ha traducido recientemente las elegías de Friedrich Hölderlin y al joven poeta alemán Arne Rautenberg, no ha reflexionado nunca por escrito sobre su práctica de la traducción, parece clara su preferencia por una práctica notablemente libre, aceptando que la traducción no es sino reescritura ${ }^{2}$, y siguiendo a Yves Bonnefoy, que propusiera no centrarse en «los enmarañamientos semánticos del material textual, sino en el ritmo, esa música de los versos, ese entusiasmo del material sonoro» (2002: 34). Parece lógico, por ello, que en la traducción

\footnotetext{
1 Para un completo estudio sobre la obra del poeta nacido en Praga, véase Gutiérrez Rubio (2010).

2 García Román se sitúa así en consonancia con los teóricos más aceptados en los estudios traductológicos, que consideran el concepto de «fidelidad» en la traducción como una aporía, pues la traducción no puede ser sino una «reescritura» (rewriting) de la obra original. Véase sobre estas cuestiones Lefevere (1992).
} 
«Médula en traducción». Rilke, Creeley y Jaccottet en tres poetas españoles...

de García Román se pierdan las abundantes paronomasias y juegos de palabras como, por ejemplo, «kosten/köstliches» («probar/deliciosa»):

Hinweg, die ich bat, endlich mein

[Lächeln zu kosten,

(ob es kein köstliches wäre)
Atrás a todos esos que invité

a probar finalmente mi sonrisa

(aun cuando ésta no fuera deliciosa)

(Rilke 2008: 40-41).

Igualmente, dadas las grandes diferencias entre las estructuras sintácticas del alemán y el español, García Román renunció a trasladar o al menos evocar un recurso muy frecuente en Rilke, como es diferir la enunciación del sustantivo principal, creando un efecto como de bola de nieve que en los versos alemanes suscita una emoción ligada a la espera de la palabra nuclear. Así, en «An den Engel» («Al ángel»), cuando Rilke dice: «Starker stiller an den Rand gestellter / Leuchter » ${ }^{3}$, García Román traduce: «Alzado candelabro, rotundo sobre el límite y sereno» (Rilke 2008: 42-43). En otros casos, el cambio de orden sintáctico cambia completamente el sentido del poema, por ejemplo en estos versos iniciales de uno de los Poemas a la noche:

Einmal nahm ich zwischen meine Hände Un día yo tomé tu rostro entre mis manos.

dein Gesicht. Der Mond fiel darauf ein. L La luna entraba en él.

(Rilke 2008: 30-31)

Como puede verse, en la traducción de García Román se pierde totalmente el efecto que produce la detracción de «tu rostro» al segundo verso y a la situación en final de frase. Sin embargo, en una estrofa posterior del mismo poema, el granadino reproduce fielmente:

Und doch war kein Wesen in der kalten

Nacht, das mir unendlicher entgeht.
Sin embargo, ningún ser en la fría

noche se me escapaba más infinitamente.

(Rilke 2008: 31)

En la traducción de «Die spanische Trilogie», en su última frase, que en alemán era «Der Tod fände sich reiner zurecht» (Rilke 2008: 50), García Román traduce, en dos versos: «Hallaría así la muerte / menos confusamente su camino» (Rilke 2008: 51). De este modo se pierde el juego de palabras entre «reiner» y Rainer, nombre del poeta, que dotaba de una sombría connotación al original. Relacionado con esto está la otra gran limitación que puede observarse en la traducción que hace García Román de Rilke, y es la creación de paráfrasis para sustituir los misteriosos epítetos rilkeanos. Así, cuando en un poema se habla de ofrecer las alas del corazón a «der Stille, der Verliererin» (literalmente, «al silencio, el perdedor»), el granadino traduce por «al silencio que juega a perder».

Se puede concluir que, si para el poeta, según Miguel Casado, «no se traduce para conservar un texto ni para difundirlo, sino para hacerlo materia personal, experiencia de vida» (Casado 2009: 106), en el caso de García Román, el ejemplo de Rilke fue decisivo en su trayectoria poética, pero sus traducciones del poeta alemán, hasta ahora, no marcan un hito como sí hicieron las realizadas por José María Valverde, Jenaro Talens o Clara Janés.

\footnotetext{
Todas las negritas de las citas son nuestras.
} 


\section{2. «Un acto simultáneo de exilio y repliegue» de Creeley a Canteli}

Por su parte, el asturiano Marcos Canteli (Bimenes, 1974), se familiarizó con las vanguardias poéticas norteamericanas durante su estancia de siete años en la Duke University, donde realizó su tesis doctoral. Canteli se interesó especialmente por la Generación Beat y por el grupo de la Black Mountain Review, especialmente Charles Olson y Robert Creeley. Canteli entrevistó a este último en 2001, al empezar la traducción de su poemario Pieces (1968), que se publicó en el año 2005, pocos meses después del fallecimiento de Creeley, y que es hasta ahora el único libro poético del poeta norteamericano traducido al castellano. Precisamente, en su tesis doctoral, Transitar el parpadeo. Seis poetas españoles (2008), al hablar de la faceta traductora de poetas como José-Miguel Ullán, Ildefonso Rodríguez, Miguel Casado u Olvido García Valdés, Canteli expone su concepto de la traducción como un «acto simultáneo de exilio y repliegue: salir a buscar lo otro y entrar al repliegue de la lengua, cargándola de posibilidades inéditas» (Canteli 2008: 245). Sin duda, Canteli estaría de acuerdo con un poeta y crítico muy cercano a él, como es Miguel Casado, en que las traducciones sirven para salir de los límites de la tradición literaria nacional, y en que «la traducción incorpora una extrañeza que abre el aprendizaje de la extrañeza que toda poesía forzosamente es; lo extranjero es la cuña que hiende la tradición heredada en lengua personal» (Casado 2009: 109). De hecho, la poesía de Creeley influyó a Canteli en la evolución de su poesía que se ha hecho patente en su penúltimo libro, Catálogo de incesantes (2009), donde los poemas forman «teselas», «mallas» o «ikebanas». En la cubierta posterior de Pedazos, la descripción de la poesía de Creeley se acerca al mismo tiempo a la poética que por entonces había asumido Canteli:

Pedazos tal vez sea la obra que mejor articula el pensamiento del poema en cuanto centro de energía, de la escritura concebida como proceso y campo compositivo, escritura del continuum, membrana sensible. Ajeno al encorsetamiento y prestigio de formalismos caducos, el poema, el libro de Creeley, es simultaneidad y amalgama (trozos, costuras, retales), elipsis de un flujo y locus de experiencia (Creeley 2005).

Aunque Canteli no haya escrito, como sí hizo García Román, sobre el influjo de Canteli sobre su poesía, hay que entender que, si aparece esta influencia, es de nuevo por una afinidad entre la búsqueda del asturiano y lo que encontró en la poesía del norteamericano. En ésta, como en la del propio Canteli, el texto poético es concebido como «espacio de conflicto, donde conceptos como sujeto, lengua o realidad son una pregunta» (Canteli 2008: 246). Y es que, como afirmara Yves Bonnefoy a propósito de las razones de un poeta para escoger traducir a otro: «Hemos traducido cuando sentimos que no hay nada en la página que no podamos percibir como nuestra propia voz, que se sueña a sí misma, entonces, libre de sus faltas en virtud del habla de un otro» (Bonnefoy 2002: 10). Hay una imagen que llama la atención en Catálogo de incesantes, al hablar de «mi médula en traducción» (2009: 26), y que podría evocar dos famosos versos de Unamuno donde habla de «el tuétano intraducible / de nuestra lengua española» (Paz 1971: 11) para afirmar precisamente lo contrario, la posibilidad de la traducción, incluso de lo más idiomático, a partir de una identificación cordial con el poeta traducido.

Aunque la traducción realizada por Canteli se deja llevar en alguna ocasión por el gusto de una selección léxica algo castiza, por ejemplo traduciendo el título Pieces, como Pedazos, o «the drinking gourd» por «la jícara» (Creeley 2005: 29), habitualmente se sigue con máxima fidelidad al texto, prefiriendo casi siempre el término castellano más cer- 
cano al original, aunque sea más inusual, por ejemplo al utilizar «presente» en lugar de «regalo» para mantener el juego de palabras del original:
A Christmas
Un presente
present-all
navideño - itodo
present and ac-
presente $\mathrm{y}$ bien
ccounted for? Sir?
justificado? ¿Señor?
(Creeley 2005: 30)

Sorprendentemente en un poeta tan experimental como el asturiano, éste renuncia a reproducir algunos juegos léxicos como las frecuentes separaciones del significante en este poemario de Creeley. En su traducción, Canteli habitualmente elimina estos seccionamientos de la palabra, como puede verse en los dos ejemplos siguientes:

$\begin{array}{ll}\text { reaching in } & \text { llegando adentro } \\ \text { from out- } & \text { desde } \\ \text { side, out } & \text { afuera, afuera } \\ \text { from in- } & \text { desde } \\ \text { side-as } & \text { adentro-como } \\ \text { middle } & \text { medio }\end{array}$

(Creeley 2005: 17).

The serial diminish-

ment or progression of

the products which

helped me remember

\section{La disminución en}

serie o la progresión de

los productos que me

ayudaban a recordar

(Creeley 2005: 50).

O en éste, donde por el contrario el asturiano refleja en su traducción el inusual alargamiento de la exclamación malsonante.

Shee-it. The world,

dad, is where you

live unless you've for-

gotten it through that
Mieeer-da. El mundo,

papá, es donde

vives a menos que lo hayas

olvidado a través de esos

(Creeley 2005: 66).

Curiosamente, Canteli intentará provocar estos efectos, separando palabras en poemas en los que aparecían de forma normal. Así, los versos: «So tired / it falls / apart». Son traducidos: «Tan cansado / se des- / hace» (Creeley 2005: 71). Ello resulta coherente con una idea de la traducción en la que, aunque se tiende a la literalidad (al contrario que, por ejemplo, en García Román), se considera primordial el reproducir el ritmo sincopado, el estilo inconfundible de Creeley. Inevitablemente, en una traducción del inglés al español se pierdan relaciones fónicas que conllevaban particulares efectos de sentido, como las paronomasias, muy habituales en Creeley. Por ejemplo, la paronomasia «mine/ mind» tan sugerente en el original: «to make you / mine, in the mind, / to know you», traducida por Canteli como «así poder / hacerte mía, en la mente, / para conocerte» (Creeley 2005: 38). De todos modos, cabe concluir que la traducción de Pieces, en la que 
resultaba extremadamente difícil reproducir el ritmo y los efectos de sentido, ${ }^{4}$ es solventada brillantemente, y a ello coadyuvó, sin duda, la cercanía de las poéticas del traducido y el traductor.

\section{3. «Una transacción secreta» de Philippe Jaccottet a Rafael-José Díaz}

Seguramente, entre los poetas españoles nacidos después de 1970, no haya ninguna labor tan continuada y extensa de traducción de un poeta como la que Rafael-José Díaz (Santa Cruz de Tenerife, 1971) ha dedicado al suizo Philippe Jaccottet (Moudon, 1925), de quien ha traducido una docena de libros. Díaz, que fue lector de español en Jena y Leipzig, conoció la poesía de Jaccottet al comprar un libro suyo en París. En su «Nota sobre la traducción", incluida en su traducción del poemario À la lumière d'hiver, el poeta canario testimonia de cómo, durante varios meses, «convivió» con el texto de Jaccottet, llevando a cabo «una lectura detenida, micrológica, desplegada en un ritmo singular: el de la fascinación y la metamorfosis» (Jaccottet 1997: 17). Díaz describe el proceso de asimilación previo al comienzo de la labor del traductor, «un proceso de interiorización de la palabra sin el cual, en mi opinión, no puede existir traducción alguna» (Jaccottet 1997: 17). En pocos poetas se da una vivencia tan intensa de la traducción, como experiencia incluso física, como íntima convivencia y lucha dialéctica con una poesía cercana al sentir del traductor y a la vez lejana en su expresión, que el canario describe con la imagen del frágil puente tendido entre las dos lenguas:

A veces el puente que va de la palabra remota (extranjera) a la palabra íntima no lograba tenderse, o era tan frágil que se derrumbaba al menor golpe de viento; otras veces, en cambio, ese puente lograba unir los extremos irreconciliables, iluminando de este modo el horizonte de la traducción (Jaccottet 1997: 17).

Y, aunque Díaz negará que los poemas traducidos formen parte de la propia obra creativa, resulta evidente la influencia que la dedicación intensa y prolongada a la traducción de Jaccottet ha ejercido sobre el poeta canario, facilitada por las circunstancias. Así, Rafael-José Díaz traduciría À la lumière d'hiver durante los largos meses de invierno en Leipzig, al tiempo que escribía los poemas que compondrían su segundo poemario, Llamada en la primera nieve (2000). La dedicación de Díaz durante casi quince años a la obra de Jaccottet ha sido acompañada de una cada vez mayor amistad entre ambos poetas y ha tenido un relevante corolario al ser Díaz leído y apreciado por el poeta suizo, quien en su prólogo «L'ébauche, à peine, d'un salut», antepuesto a Le crépitement, antología de poemas de Díaz traducida al francés, muestra la afinidad que le une al poeta canario:

Ce qui m'a retenu, avant toute autre chose, dans ces beaux poèmes, c'est, même là où il leur arrive d'approcher les confins déchirants de la mort ou ceux, à peine moins déchirants, de l'absence, une diction étonnament calme, un pas miraculeusement léger [...] Des paroles claires et simples, mais qui, dans leur cours tranquille, touchent presque toujours au seuil obscur qu'elles ne peuvent que montrer et non franchit (Jaccottet 2007b: 7-8).

Jaccottet ve con precisión las claves de la concepción del «umbral» o «seuil», que marca lo que podría llamarse una «poética de la liminalidad» que Díaz ha seguido de manera muy coherente desde su primer poemario, significativamente titulado El canto en el umbral (1997). Para Díaz, el «umbral» evoca y resume toda la conciencia de liminalidad de la actividad creadora, concebida por el autor como «un espacio invisible» que es «el hueco

\footnotetext{
4 En conversación de noviembre de 2010 con el autor, éste afirmó que «fue una traducción endiablada».
} 
«Médula en traducción». Rilke, Creeley y Jaccottet en tres poetas españoles...

de la voz, el cóncavo corazón de la palabra que nace para que la mano la dibuje, sola, en la intimidad de la noche, en las inciertas proximidades del sueño» (Díaz 2006: 181-182). De manera más general, es evidente que tanto Díaz como Jaccottet son dos poetas contemplativos, esencialmente visuales, que asisten a signos que sienten «como los secretos pasajes o aberturas que, a través de lo visible, conducen a lo invisible» (Díaz 2007a: 136), iluminaciones necesariamente fragmentarias, pero que se justifican en su belleza. Pero las afinidades no se terminan ahí, sino que ambos poetas coinciden igualmente en haber recurrido a la prosa en determinadas ocasiones para decir cosas que podían decir mejor que en verso. Así, si en su peor periodo de crisis existencial, Jaccottet recurrió a la narración para escribir la desgarrada novela L'Obscurité (1961), Díaz, igualmente en un momento de profunda crisis, recurrió también a la narrativa, escribiendo su novela $E l$ interior del párpado, aún inédita.

A continuación veremos algunos ejemplos del modo en que Díaz trató de tender el frágil «puente» entre las lenguas francesa y española. El francés, por su cercanía fónica, plantea obviamente otras dificultades que el alemán o inglés, hasta el punto de permitir, en ocasiones, que el traductor permanezca fiel a la rima del poema original:

Elle est le jour sur l'écorce

Es el amanecer en la corteza

l'amour qui se dissémine

el amor que se disemina

peut-être la clarté divine

tal vez la claridad divina

à qui la hache donne force.

a la que el hacha da fuerza

(Jaccottet 2010: 36-37).

En otras ocasiones, inevitablemente, la rima es irreproducible y con ello se pierde el poder de asociación que ésta evoca, por ejemplo en los versos siguientes, donde la traducción hace que se pierda la oposición entre los dioses y lo exterior, propia de la sensibilidad de Jaccottet, movida por las sensaciones naturales sin necesidad de lo ultraterreno.

(Chose brève, le temps de quelques

[pas dehors,

mais plus étrange encore que les mages

[et les dieux)
(Cosa breve, el tiempo de algunos

[pasos afuera

pero más extraña aún que magos

[y dioses)

(Jaccottet 2007a: 40-41).

Más difícil aún es mantener los efectos de las aliteraciones, que se pierden, por ejemplo, al traducir «le beau mur bleu» por «el bello muro azul» o los «signes / hésitants, inquiets, de chauve-souris» por «signos / de duda, inquietos, zigzagueantes» (Jaccottet 2007a: 3435), perdiendo la imagen de los murciélagos. O bien, en Cuaderno de verdor, al comparar una tormenta nocturna con «un bruit d'ossements qu'on remuerait», Díaz traduce como «un ruido de huesos removidos» (Jaccottet 2005: 46), perdiéndose las connotaciones de mayor tamaño que habría tenido que traducir «osamentas», al tiempo que el verbo «remuerait», puede asociar con «mourait», asociación perdida en castellano. En otras ocasiones, el término francés, elegido por su sonoridad, tiene un equivalente español muy diferente. Por ejemplo, la asociación entre «mésanges» y «anges», mantenida con esfuerzo con «alionín» y «querubín», resulta algo rebuscada y no tan natural como en francés (Jaccottet 2005: 71). Lo mismo ocurre al traducir «serpe» por «hocino» (Jaccottet 2005: 76). En otro momento del poema «Sobre los peldaños ascendentes», Jaccottet describe el canto de los pájaros aun invisibles que parecen pugnar por querer hacer subir el día y los 
compara con cohetes, «réduits aux fusées de leurs cris infatigables» (2005: 45). La traducción de Díaz, «reducidos a los cohetes de sus gritos incansables», aunque semánticamente irreprochable, no contiene en «cohetes» la sonoridad y las asociaciones del original en el eje paradigmático, por ejemplo con «fusión». En el mismo poema, sin embargo, la traducción puede mejorar algún término no tan lírico. Cuando el poeta suizo dice que los pájaros «s'activaient à soulever la dalle», el canario traduce «se daban prisa en levantar la losa» (Jaccottet 2005: 45), dando una imagen de apresuramiento en los momentos previos al amanecer más acertada, quizás, que la simple actividad del verso original.

De hecho, a veces, la traducción introduce matices perfectamente de acuerdo y que incluso suman al estilo de Jaccottet, como cuando, en un poema de los Cantos de abajo, se dirige a sí mismo en imperativo por escribir la belleza que le rodea: «relie, tisse en hâte, encore, habille-nous», como «religa, teje, no tardes, vístenos» (Jaccottet 2007a: 34-35). También resulta original e intensifica el poema al traducir «trop de rébus» por «demasiados jeroglíficos» (Jaccottet 2007a: 50), ya que a continuación el poeta prosigue: «Siento que cada día soy más ignorante / con el tiempo / y seré pronto un imbécil entre los zarzales» (Jaccottet 2007a: 50). En cambio parece poco acertada la traducción del título «Éclats d'août» por «Fragmentos de agosto», en lugar de por «destellos» que simplifica la connotación de estallido del original. Además, se pierde la diferencia instituida por Jaccottet, cuya sección siguiente se llama, ésta sí, «Fragments soulevés par le vent» (Jaccottet 2007a: 53-60). O, por ejemplo, en El ignorante, al traducir Díaz «un corazón asediado por la muerte» el original «le coeur où la mort s'affaire» (Jaccottet 2007a: 54-55), varía el significado inicial, en el que la muerte ya está en el corazón, se afana dentro de él, para sustituirlo por una imagen externa, aunque no por ello menos inquietante.

En algunas traducciones, el poeta-traductor introduce efectos ausentes de la versión original, por ejemplo convirtiendo un cuarteto de versos heptasílabos uniformes en una copla de pie quebrado. El efecto, sin embargo, resulta afortunado:

$\begin{array}{ll}\text { Je ne voudrais plus qu'éloigner } & \text { No desearía ya sino alejar aquello } \\ \text { ce qui nous sépare du clair, } & \text { que nos separa de lo claro, } \\ \text { laisser seulement la place } & \text { dejar sólo el espacio para la desdeñada } \\ \text { à la bonté dédaignée } & \text { bondad } \\ & \text { (Jaccottet 1997: 28-29). }\end{array}$

En otros desvíos del original, más frecuentes en sus primeras traducciones, Díaz se deja llevar por el prurito de buscar una sonoridad más variada, quebrando con ello los efectos de insistencia monótona sobre la «ordure» (basura) o sobre el desgarramiento deliberadamente buscados por Jaccottet:

On peut nommer cela horreur, ordure prononcer même les mots de l'ordure

On le déchire, on l'arrache, cette chambre où nous nous serrons [est déchirée
Se puede llamar a esto horror, inmundicia, incluso pronunciar las palabras del asco (Jaccottet 1997: 44-45).

Lo desgarran, lo despedazan este cuarto en que estamos encerrados [sangra

(Jaccottet 1997: 50-51) 
«Médula en traducción». Rilke, Creeley y Jaccottet en tres poetas españoles...

En sus últimas traducciones, Rafael-José Díaz ha buscado una fidelidad lo más cercana posible al original de Jaccottet, en lo cual siguió el mismo criterio defendido por el poeta suizo en su libro Une transaction secrète (1987). Precisamente en un ensayo, en homenaje a aquel libro, titulado, «Una transacción secreta: Leer y traducir a Philippe Jaccottet», Díaz reflexiona sobre su idea de la traducción, declarando que, al traducir a Jaccottet, «la dicotomía entre fidelidad y originalidad, entre lo que se denomina la traducción filológica y la traducción creadora, no me era suficiente para enfrentarme a los textos de este autor. Había que dar un paso más allá, intentar instalarse de algún modo en la raíz del soplo, en el origen de las imágenes, en el umbral del canto» (Díaz 2007b: 21). Como puede verse, la poética de la liminalidad que caracteriza la obra de Rafael-José Díaz ${ }^{5}$ abarca también su idea de la traducción, por la cual habría que intentar situarse en la experiencia liminal del poema original para saber traducirlo. Sin embargo, Díaz niega «que los poemas traducidos formen parte de la propia obra creativa» pues «los impulsos, las motivaciones, las búsquedas y los procesos de ambas actividades son radicalmente distintos» (Díaz 2007b: 21). La labor del traductor está marcada por la modestia, al limitarse a ser «un passeur» alguien «que pasa las palabras de una orilla a la otra, en un barquero que, en medio de un Leteo babélico, custodia e intenta trasladar en su frágil barca un inmenso tesoro impalpable: el alma de las palabras» (Díaz 2007b: 22). Como podemos ver, la modestia que implica la condición de intermediario convive con la ambición de apresar algo tan inasequible como «el alma de las palabras», algo revelador de la confianza en el lenguaje como medio de indagación de algunos de los mejores poetas españoles actuales.

\section{Conclusión: «Traerte a tu terreno», o la traducción como forma de ampliación de la tradición poética}

Como ha podido comprobarse, los tres poetas seleccionados tienen ideas muy distintas respecto a la traducción. Frente al concepto de fidelidad al poeta traducido y del papel del traductor como un passeur que defiende Rafael-José Díaz, para un poeta como Juan Andrés García Román, esta cuestión no se plantea, pues la traducción es una rescritura, siguiendo una posición afirmada con vigor por Henri Meschonnic, quien denostara la idea del traductor como passeur, y estableciera como criterio de validez de una traducción que funcionara como un texto, tan transformado como se quisiera, mientras contuviera el significado central del texto traducido (Meschonnic 1999: 18-64). Pero más allá de los cuestionamientos sobre algunas decisiones de estos poetas al traducir a unos autores con los que sentían una especial afinidad, importa, a mi modo de ver, el mero hecho de la elección particular de estos poetas y no otros. Como dijo otro notable poeta y traductor, Jenaro Talens, «traducir es traerte a tu terreno lingüístico, cultural, incluso político y sentimental, algo que fue pensado y escrito en otro contexto, para otro público y seguramente con otras expectativas» (Talens 2002: 107). En este sentido, los errores, como sigue diciendo Talens, no son perjudiciales, sino que pueden revertir en innovaciones valiosas, pues traducir «obliga a forzar los esquemas de tu propia lengua y eso enriquece la tradición propia. Cuanto más ha traducido una lengua, más rica y flexible resulta para la poesía. Yo diría, incluso, que la historia de la poesía es la historia de los malentendidos de la traducción» (Talens 2002: 107). Frente a la práctica limitación a la

Puede verse a propósito de su poesía mi breve ensayo (Martín Gijón 2012). 
«tradición española» en los poetas que provienen de la tendencia de la «poesía de la experiencia», los tres poetas que hemos tratado, representantes de lo que podríamos llamar «poesía de indagación» muestran, en su diálogo continuado con tres grandes poetas de las literaturas de lengua inglesa, alemana y francesa, su propósito definido de ampliar los límites del lenguaje poético en español.

\section{Bibliografía}

Bonnefoy, Yves (2002), La Traducción de la Poesía, traducción y prólogo de Arturo Carrera, Valencia: Pre-Textos.

CANTELI, Marcos (2003), Enjambre, Madrid: Bartleby Editores.

Canteli, Marcos (2008), Transitar el parpadeo. Seis poetas españoles, Duke: Duke University Press.

[http://dukespace.lib.duke.edu/dspace/bitstream/10161/591/1/D_Canteli\%20 Vigon_Marcos_a_200805.pdf. Consultada por última vez: 26/11/2012].

CAnTeli, Marcos (2009), Catálogo de incesantes, Madrid: Bartleby Editores.

CASADO, Miguel (2009), La experiencia de lo extranjero. Ensayos sobre poesía, Barcelona: Galaxia Gutenberg.

Creeley, Robert (2005), Pedazos, traducción de Marcos Canteli, Madrid: Bartleby Editores.

DíAz, Rafael-José (2006), «La mano a contraluz: fragmento para una antepoética». Última poesía española (1990-2005). Antología, edición de Rafael Morales Barba, Madrid: Marenostrum, 181-182.

DíAz, Rafael-José (2007a), «La siembra silenciosa: Sobre Philippe Jaccottet», Rutas y rituales, edición de Rafael-José Díaz, Santa Cruz de Tenerife, Ediciones Idea, 135-142.

DíAZ, Rafael-José (2007b), «Una transacción secreta: Leer y traducir a Philippe Jaccottet». Poesía en traducción. Ed. Jordi Doce y Miguel Gallego Roca. Madrid: Círculo de Bellas Artes, 17-42.

García RomÁn, Juan Andrés (2008), «Un lugar entre lo posible y lo imposible». Deshabitados. Ed. Juan Carlos Abril. Granada: Diputación de Granada, 217-226.

Gutiérrez Rubio, Enrique (2010), Conocer a Rilke, Madrid: Laberinto.

Jacсоттет, Philippe (1997), A la luz del invierno, introducción y traducción de RafaelJosé Díaz, Palma de Mallorca: Calima Ediciones.

Jaccotтeт, Philippe (2005), Cuaderno de verdor, traducción de Rafael-José Díaz, Madrid: Bartleby Editores.

JACсоTтET, Philippe (2006), El ignorante. Poemas. 1952-1956, traducción y prólogo de Rafael-José Díaz, Valencia: Pre-Textos.

JAccotTet, Philippe (2007a), Cantos de abajo, prólogo de Juan Barja, traducción y epílogo de Rafael-José Díaz, Madrid: Círculo de Bellas Artes.

JACCOTTET, Philippe (2007b), «L'ébauche, à peine, d'un salut», prèface à RafaelJosé Díaz, Le crépitement. Poèmes (1992-2000), traduits par Jacques Ancet, Bernard Banoun, Roberto San Geroteo, Claude Held et Guy Rochel, Chauvigny: L'Escampette, 5-10.

Jaccottet, Philippe (2010), Aires. Poemas 1961-1964, traducción y prólogo de RafaelJosé Díaz, Badajoz: Fundación Ortega Muñoz. 
LEFEVERE, André (1992), Translation, Rewriting, and the Manipulation of Literary Fame, Londres: Routledge.

Martín Gijón, Mario (2012), «Una poética de la liminalidad. La trayectoria de Rafael-José Díaz», Hipertexto 15: 90-102.

Meschonnic, Henri (1999), Poétique du traduire, París: Verdier.

Mora, Vicente Luis (2009), «10 notas para explicar(me) El fósforo astillado». Diario de lecturas, 26 de febrero de 2009.

[http:/ / vicenteluismora.blogspot.com/2009/02/10-notas-para-explicarme-elfosforo.html]

PAz, Octavio (1971), Traducción: literatura y literalidad, Barcelona: Tusquets.

RILKE, Rainer Maria (2008), Poemas a la noche y otra poesía póstuma y dispersa, edición y traducción de Juan Andrés García Román, Barcelona: DVD Ediciones.

Talens, Jenaro (2002), Negociaciones para una poética dialógica, Madrid: Biblioteca Nueva.

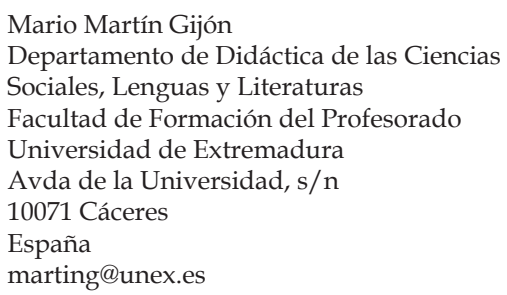

